BLS 32, No 1 2006. DOI: http://dx.doi.org/10.3765/bls.v32i1.3479 (published by the Berkeley Linguistics Society and the Linguistic Society of America)

\title{
Plurality of Events: Parallels between Language and Perception
}

\author{
TESS WOOD \\ University of California, Berkeley
}

\section{Introduction}

Grammatical markers of event plurality ('pluractionality') express repetition of events in time or space, or across distinct participants. In this paper I address a contrast between two types of pluractional meaning which are found across languages: repetition of events, and repetition within a single event (Cusic 1981). Based on the findings of a survey of over 40 languages, I argue that this contrast has its basis in a distinction between grouped and ungrouped pluralities, with a process of group-formation similar to that described by Gestalt psychologists in visual perception. I also propose that it can be integrated with analyses of nominal plurality, and specifically that it is parallel to the collective-distributive distinction in plural NPs.

Grammatical marking of plural events occurs in a wide range of languages (cf. Dressler 1968, Cusic 1981, Xrakovskij 1997, among others). The examples in (1) and (2) from Chechen and Finnish illustrate the basic contrast between single and pluractional verbs. In Chechen the pluractional is marked by ablaut, in Finnish by one of several suffixes.

(1) Chechen (Yu 2003:293)

\begin{tabular}{|c|c|c|c|}
\hline & 'to pour' & d.yttu & 'to pour repeatedly' \\
\hline & 'to drink' & myylu & 'to drink repeatedly' \\
\hline & 'to $\mathrm{sr}$ & tieba & 'to sneak up repeatedly' \\
\hline & 'to thunder' & q'ieq'a & 'to thunder repeatedly' \\
\hline
\end{tabular}

(2) Finnish (Karlsson 1999:239)

$\begin{array}{llll}\text { ajaa } & \text { 'drive' } & \text { ajella } & \text { 'drive around' } \\ \text { astua } & \text { 'step' } & \text { astella } & \text { 'step, walk around' } \\ \text { kysyä } & \text { 'ask' } & \text { kysellä } & \text { 'ask repeatedly' } \\ \text { oppia } & \text { 'learn' } & \text { opiskella } & \text { 'study' }\end{array}$

Cross-linguistically, pluractional meanings have been argued to fall into two main types. Cusic (1981:67) distinguishes plurality internal to an event (i.e. a 


\section{Tess Wood}

single event consists of repeated phases) from plurality external to an event (i.e. a single bounded event is repeated, either on one occasion or multiple occasions). Following Garrett (2001), I use the terms "event-internal" and "event-external" to refer to these two types of meaning.

The examples in (3) to (6) illustrate these two types of pluractional meaning.

(3) Event-internal repetition: Koasati -ci (Kimball 1991:329-330)

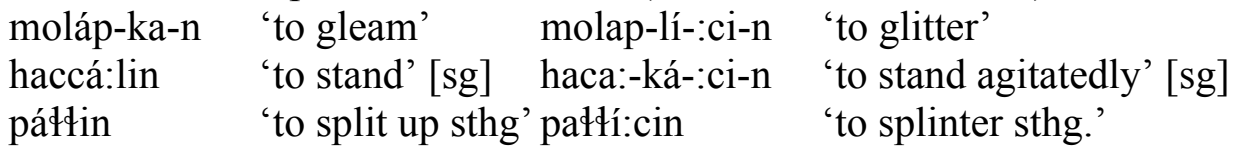

(4) Event-internal repetition: Yup'ik -\%ur- postbase (Jacobson 1984:581)

kaleg- 'to brush against' kalguraa 'he is strumming it'

naveg- 'to break' navguraa 'he is wrecking it'

(5) Event-external repetition: Hausa (Newman 2000:423-424)

tùna 'remind' tuntùna 'remind many or often'

hàifā 'give birth' hàhhaifà 'give birth many times/to many children'

(6) Event-external repetition: Yup'ik -qaqe-postbase (Jacobson 1984:535)

nere- 'to eat' nerqaqluniq 'eating now and then'

quuyurni- 'to smile' quuyurniqa'aqluni 'smiling now and then'

ayag- 'to go' ayakaqluni 'moving now and then from place to place'

For example, the Yup'ik postbase exemplified in (4) applies to the verb naveg- 'to break' with an event-internal pluractional meaning. Its effect is to indicate a complex event consisting of repeated breaking, which amounts to an instance of 'wrecking.'

The Hausa verb reduplication in (5) produces a meaning of event-external repetition. For instance, when reduplicated, hàifă 'to give birth' indicates multiple distinct events of giving birth.

\section{Characteristics of Event-Internal Pluractionals}

Pluractionals construe repetition either as a sequence of separate events or as a single event with multiple internal phases. However, actual instances of repetition are not inherently divided into these two types. Therefore, the question arises of what properties of repeated occurrences require or predispose them to be construed as forming a single, complex event rather than as a sequence of events. Comparing the uses of event-internal pluractionals across languages reveals certain patterns in the types of events and the types of contexts which occur with these single-event interpretations, as will be outlined in this section.

While the relative importance of these characteristics and their interactions undoubtedly varies from language to language, the general pattern is clear, and 


\section{Plurality of Events in Language and Perception}

can contribute to an understanding of the semantics of the contrast between eventinternal and event-external pluractionals.

\subsection{Pluralization of Arguments}

The typical interpretation of most pluractionals is one of repetition in time. However, in addition to this basic meaning, many pluractionals also have interpretations in which they pluralize a participant. ${ }^{1}$ In these cases, event-internal and event-external pluractionals show different behavior. Yurok has two pluractionals: one, an infix -eg-, has event-external meaning (7); the other, a reduplicative prefix, has event-internal meaning (8) (examples from Garrett et al. 2005).

(7) Yurok event-external pluractional (-eg- infix)

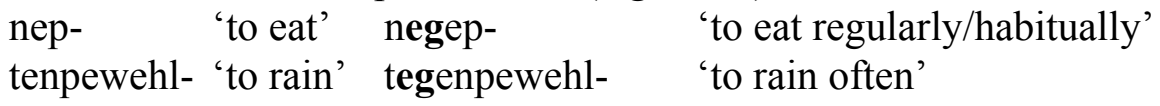

(8) Yurok event-internal pluractional (reduplication)

menoot 'to pull' menomenoot 'to keep pulling'
prkwrh(s)- 'to knock'

The examples in (9) and (10) show the plural-participant interpretations of each of the pluractionals.

(9) Event-external pluractional

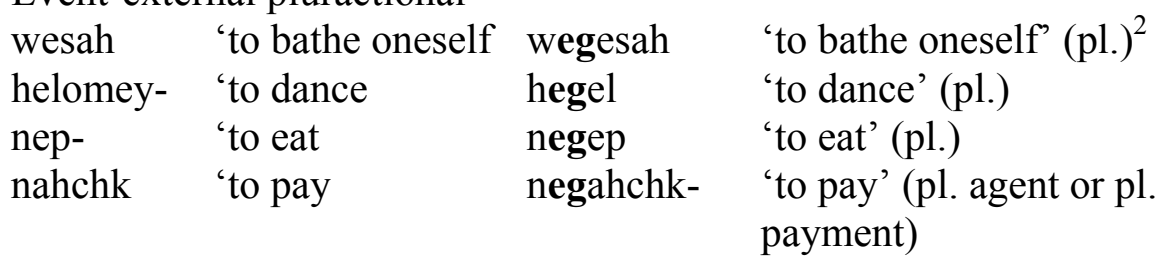

(10) Event-internal pluractional

$\begin{array}{llll}\text { tekws- } & \text { 'to cut' } & \text { tekwtekws } & \text { 'to cut' (pl. object) } \\ \text { yekwoh(s-) } & \text { 'to fold' } & \text { yekwoyekwoh(s-) } & \text { 'to fold' (pl. object) } \\ \text { ket'ey } & \text { 'to park, moor' } & \text { ket'ket'ey } & \text { 'to lie (of boats) }\end{array}$

The event-external infix can pluralize any participant, but commonly pluralizes subjects of transitive and unergative intransitive verbs. Event-internal reduplication, on the other hand, only produces plural interpretations of objects of transitive verbs and subjects of unaccusative intransitives.

The pattern seen in Yurok is typical. Event-external pluractionals, when they

\footnotetext{
1 There are languages with pluractional categories which have exclusively plural-location or plural-argument meanings, but I will not discuss these here.

2 All of the examples in (9) and the first two examples in (10) also permit an interpretation of repetition in time (involving a single participant). In some cases this is the preferred reading.
} 


\section{Tess Wood}

pluralize participants, often pluralize an Agent/external argument. They may also pluralize other arguments but tend to suggest a strongly distributive interpretation ('do to each'), and commonly refer to humans or other highly individuated entities. This can be seen in example (11) from Yimas, in which the pluractional (reduplicated) verb pluralizes an animate direct object.

\section{(11) Yimas (Foley 1991:319) \\ pu-kra-nanay-tarat-awram-tut} 3PL A-1PL O-DUR-hold(RED: tal-)-enter-RM PAST

'They were holding (each one of us), as they entered.'

Event-internal pluractionals, on the other hand, pluralize Patient/internal arguments, and often the pluralized argument is of low individuation and the pluractional verbs are translated as 'do to a lot of things', 'do to all', rather than 'do to each'.

\subsection{Proximity}

Repetitions which are continuous or closely spaced in time are more likely to be construed as constituting a single event than those spaced further apart. Eventinternal pluractionals are never distributed across separate occasions (this is in fact a definitional property according to Cusic), and generally do not indicate intermittent action. Event-external pluractional interpretations often involve distribution over occasions or intermittent action on a single occasion. The Yup'ik pluractionals in (4) and (6) above illustrate this difference.

\subsection{Aktionsart}

Certain classes of events, and in particular certain Aktionsarten, are more likely than others to occur with event-internal pluractional meaning. Semelfactive predicates are commonly pluralized with event-internal pluractional meaning. Semelfactives describe events which are more-or-less instantaneous, and which do not involve a change of state or have an inherent final boundary - verbs meaning 'cough', 'kick', 'knock', 'flash', and so on. The Turkmen examples in (12) are typical.

$$
\begin{aligned}
& \text { Turkmen (Clark 1998:537) }{ }^{3} \\
& \text { } \theta \text { ilkmek to shake' } \theta \text { ilkelemek to quiver' }
\end{aligned}
$$

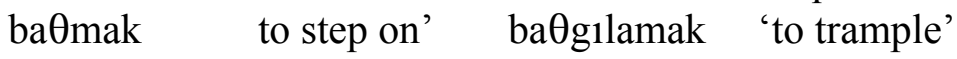

The nature of semelfactive predicates means that they are easily repeated in quick succession. As a result, when pluralized they lend themselves to an interpretation of continuous repetition. Many achievement predicates (with meanings such as 'cut', 'break') behave similarly, though often producing plural Patient

\footnotetext{
For simplicity, I use only Clark's phonemic transcriptions, not the Cyrillic orthography.
} 


\section{Plurality of Events in Language and Perception}

interpretations.

Event-internal pluractionals also occur with verbs of other Aktionsart classes. However, they almost never apply to accomplishments, or to achievements which involve a run-up phase before their final transition (such as 'die'). When they do, they pluralize only the process phase of the event, usually producing a conative interpretation. Garrett (2001) notes this pattern in Latin:

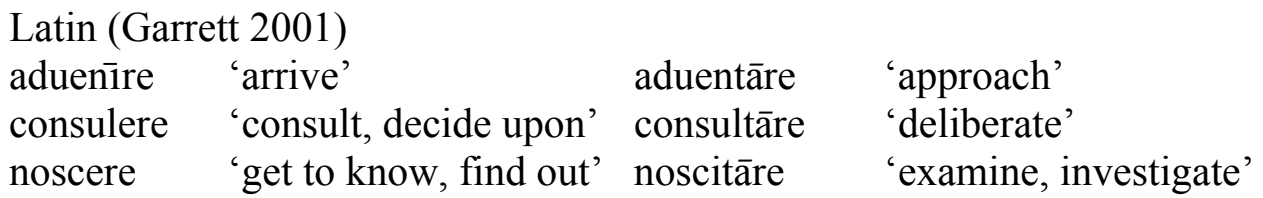

I suggest that the relevant generalization here is that event-internal pluractionals pluralize single-phase events. Events which are internally complex (such as accomplishments, consisting of a process phase and a final change of state) must undergo some sort of coercion in order to conform to this requirement.

\subsection{Typical Multiplicity}

Events which are typically repeated are more likely to occur with event-internal pluractional meaning. This includes event types such as breathing, coughing, knocking or digging, as in the Kayardild example in (14).

$$
\begin{aligned}
& \text { Kayardild (Evans 1995:290) } \\
& \text { ngawija 'breathe' ngawi-nyawi-ja 'pant' } \\
& \text { kurdala 'stab' kurdala-kurdala-tha 'digging (lit. 'stabbing') in } \\
& \text { the sand to find eggs }{ }^{4}
\end{aligned}
$$

\subsection{Common Endpoint}

Event-internal repetition has a common goal or endpoint. For instance, knocking on a door (as might be described by the pluractional verb prkwhprkwrh(s-) in Yurok, from (8) above) involves repetition with a single, specific goal. In the case of repeated action on a single Patient argument, there is a natural endpoint when the Patient is fully affected. For example, the pluractional of the Yup'ik verb naveg- 'to break' (from (4) above) means 'to wreck', and the pluractional event has a natural completion when the Patient is fully wrecked.

\subsection{Summary}

These characteristics often co-occur, and may be taken to define the typical context for event-internal pluractional interpretations. Two of the characteristics are apparently essential: in order for repetitions to be treated as the phases of a single event, they must occur in temporal or spatial proximity and must not be

$4 \quad$ I am grateful to Claire Bowern for pointing out that the meaning of this reduplicated verb is literally 'stab repeatedly', since a pointed stick is used to dig in the sand for eggs. 
Tess Wood

distributed over Agents. The other characteristics are general tendencies: the prototypical event-internal pluractional pluralizes a semelfactive-type event, and one which commonly occurs in multiple repetitions, often with a specific final boundary. However, the behavior of event-internal pluractionals when combined with accomplishment predicates appears to be consistent across languages.

Looking at the effect of these characteristics together, it can be seen that event-internal pluractionals prototypically describes repetition which has three main properties: familiarity; internal homogeneity (small parts with no complex internal structure, no large gaps between repetitions, no distribution across different Agents); and well-defined external boundaries (common goal or completion). I suggest that these characteristics are what permits the grouping of multiple parts into a complex whole.

A process of forming complex wholes from discrete perceptual entities is well-known in the study of visual perception. In the next section I examine the principles of grouping outlined by Gestalt psychologists and consider their possible relationship to the distinction between event-internal and event-external pluractionals.

\section{Gestalt Laws of Grouping}

I suggest that event-internal pluractionals involve a cognitive process of grouping, parallel to the process of grouping in visual perception described in Gestalt psychology (cf. Wertheimer 1923, Koffka 1935). The Gestalt psychologists identified several characteristics which determine the visual grouping of stimuli into a single entity. These include the "laws" of similarity, proximity, common fate, closure, good continuation and familiarity. A simple explanation and illustration of each of these principles is given below, followed by a comparison to the characteristics favouring event-internal pluractional interpretations.

\section{a. Proximity}

Objects which are close together in the visual field will be grouped together more readily than objects which are further apart. The following picture tends to be seen as three columns rather than three rows, since vertical proximity of adjacent objects is greater than horizontal proximity.

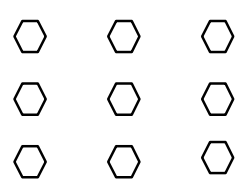

b. Similarity

Objects which are similar will be grouped together more readily than objects which are dissimilar. The following array is therefore perceived to contain an inverted $v$-shape consisting of zeros. 


$$
\begin{array}{lllllllll}
1 & 1 & 1 & 1 & 0 & 1 & 1 & 1 & 1 \\
1 & 1 & 1 & 0 & 1 & 0 & 1 & 1 & 1 \\
1 & 1 & 0 & 1 & 1 & 1 & 0 & 1 & 1 \\
1 & 0 & 1 & 1 & 1 & 1 & 1 & 0 & 1 \\
0 & 1 & 1 & 1 & 1 & 1 & 1 & 1 & 0
\end{array}
$$

\section{c. Closure}

Stimuli are grouped together if they tend to complete some closed region. Perceivers fill in gaps in incomplete figures. For example, it is easy to perceive a triangle in the arrangement of shapes in (17).

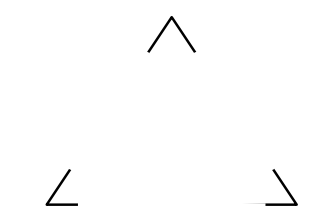

d. Good continuation

Objects tend to be grouped together when they produce a continuous line or curve, usually without abrupt changes. For instance, an $\mathrm{X}$ is viewed as two intersecting diagonal lines rather than as two $v$-shapes in opposite orientations.

\section{e. Common fate}

Objects which move or function together are grouped together. For example, (18a) is seen as a line consisting of four objects. However, if two objects (even if not adjacent) move in one direction and two in another, as in (18b), the line is perceived as being divided into two smaller groups.
a.

b.

\section{f. Familiarity}

An arrangement of objects which is familiar is more likely to be perceived as a single complex entity.

The laws governing grouping of objects tend to produce internally homogeneous, externally simple and clearly bounded structures, and give preference to structures which are familiar. These are exactly the same types of effects suggested to result from the common characteristics of event-internal pluractionals. 


\section{Tess Wood}

\section{Individuation of Events}

What has not yet been addressed is how the grouping or individuation of repetitions relates to the individuation of events from non-repetitive sequences. The problem of organizing perceived occurrences into events is quite similar to the problem of organizing perceptual stimuli in the visual field into objects. However, while literature on the perception of objects has focused on the factors favoring grouping, research on the perception of events has focused on the reverse: factors correlating with perceived event-boundaries. Drawing on findings from a range of studies on event individuation, Zacks and Tversky (2001) discuss characteristics which correlate with perceived event boundaries, some of which are summarized here.

\section{a. Perceptual discontinuity}

Studies show that subjects tend to segment events at points with the highest degree of perceptual discontinuity, i.e. maximal change in physical features of the action (Zacks and Tversky 2001:7). For example, Newtson et al. (1977) found a correlation between degree of change in position of an actor and perceived eventboundaries. It follows from this finding that periods of action with relatively high perceptual continuity are likely to be grouped together. As suggested in section 2, event-internal pluractionals tend to refer to events which are internally relatively homogeneous (i.e. repetitions with a high level of perceptual continuity).

\section{b. Unpredictability}

Sequences of occurrences are divided into larger segments if they are familiar or predictable (Zacks and Tversky 2001:8). As predictability decreases, subjects divide streams of action into smaller units (Newtson 1973). In the cases studied, these are not repeated events. However, the behavior of event-internal pluractionals suggests that, when presented with sequences of repetitions, subjects are more likely to group into a single event those which are normally or predictably repeated (i.e. which are familiar as a sequence of repetitions). This is a typical characteristic of event-internal pluractionality.

c. Change in perceived goal

Subjects place event boundaries at points of perceived change in goal (Zacks 2004, Wilder 1978a, 1978b). This finding mirrors the tendency noted above for event-internal pluractionals to refer to repetitions with a common goal or completion. Repetitions are more likely to be grouped together if they form an event with a clear completion, and this is reminiscent of the Gestalt principle of closure.

In summary, I have argued that the kinds of factors which appear to influence grouping in the two domains are very similar in nature. They are similar enough that it seems reasonable to suggest they instantiate the same general cognitive process: the creation of complex (grouped) entities from multiple stimuli. 


\section{Plurality of Events in Language and Perception}

\section{The Semantics of Grouped and Ungrouped Pluralities}

In this section, I will suggest one way in which the proposed distinction between grouped and ungrouped events may be incorporated into an existing account of plurality, adapting the analysis of Landman (1996, 2000).

Landman assumes three types of individuals: singular, plural and group. Groups (like singular individuals) are atomic, and are formed by applying a group-formation operator $(\uparrow)$ to a plural. On this view, collective NP interpretations involve groups, while distributive interpretations are plurals.

By extending this three-way distinction to events, it is possible to account straightforwardly for the pluractional contrast.

On Landman's account, the distinction between collective and distributive predication is reduced to a difference between singular and plural predication (Landman 1996:428):

(19) singular predication applies a basic predicate to an atomic (singular or group) individual

plural predication applies a plural predicate distributively to a plural sum of such atomic individuals

At the same time, Landman argues that the distinction between singular and plural predication is a distinction between thematic and non-thematic predication: a basic singular predicate is one whose argument fills a thematic role. Plural predicates have special, non-thematic "plural roles". These are sums of thematic roles: a plural agent is the sum of the agents of the atomic parts of a plural event. For example, on its collective reading, a sentence like John and Bill lifted the piano contains a singular predicate with an atomic (group) agent whose parts are John and Bill. The group as a whole fills the thematic role of agent, and neither of the individuals John or Bill by himself fills the thematic role. On the distributive reading, John and Bill are separate agents of the atomic carrying events, and together they fill a non-thematic plural role of the verb carry.

Pluractional verbs, I propose, have the same semantic distinction as plural NPs. Event-internal pluractionals are groups, while event-external pluractionals are true plurals.

(20)a. An event-external plural is a plural event (e) consisting of proper subparts (events) $\mathrm{e}_{1} \ldots . . \mathrm{e}_{\mathrm{n}}$

b. An event-internal plural is a "group atom", an event (e) whose ungrouped counterpart $(\downarrow e)$ has proper subparts $\mathrm{e}_{1} \ldots . . \mathrm{e}_{\mathrm{n}}$

The behavior of event-internal and event-external pluractionals with respect to pluralization of arguments fits nicely with such an account. Event-external pluractionals, as plural events, may combine with plural (distributive) arguments, producing an interpretation in which individual events are distributed across individual participants. Event-internal pluractionals, on the other hand, function as 
Tess Wood

atomic predicates with true thematic roles. Plural arguments can only be interpreted as collective (group).

\section{Conclusions}

In this paper I have explored a semantic distinction between two types of pluractional meaning. I have suggested that this distinction reflects two major ways of construing repetition: either as a complex, internally plural event (event-internal plurality) or as an ungrouped set of events (event-external plurality). The same grouping operation appears to be at work in the distinction between collective and distributive interpretations of plural NPs, and is also evident in the processes of visual grouping described in the work of Gestalt psychologists, as well as in the parallel (or, rather, mirror image) research on event individuation. I take these findings as broadly consistent with a view of grammar as grounded in general cognitive abilities (cf. Langacker 1987) and of conceptual structure as emerging from perceptually-based symbols (cf. Barsalou 1999, 2003). The convergence in findings from cross-linguistic data and cognitive psychology should underscore the value of exploring these connections further, e.g. in investigating the perception of repeated actions.

\section{References}

Barsalou, Lawrence W. 1999. Perceptual symbol systems. behavioral and Brain Sciences 22:577-609

Barsalou, Lawrence W., Kyle Simmons, Aron K. Barbey and Christine D. Wilson. 2003. Grounding conceptual knowledge in modality-specific systems. TRENDS in Cognitive Science 7(2):84-91

Clark, Larry. 1998. Turkmen Reference Grammar. Otto Harassowitz Verlag.

Cusic, David Dowell. 1981. Verbal Plurality and Aspect. Ph.D. diss., Stanford University.

Dressler, Wolfgang. 1968. Studien zur verbalen Pluralität. Wien: Verlag der Österreichischen Akademie der Wissenschaften.

Foley, William A. 1991. The Yimas Language of New Guinea. Stanford, CA: Stanford University Press.

Garrett, Andrew. 2001. Reduplication and Infixation in Yurok: Morphology, Semantics, and Diachrony. International Journal of American Linguistics 67:264-312.

Garrett, Andrew. 2001. The origin of the Latin frequentative. Presented at the $20^{\text {th }}$ East-Coast Indo-European Conference, Cornell University, June 2001.

Garrett, Andrew, Juliette Blevins and Lisa Conathan. 2005. Preliminary Yurok Dictionary. Ms., University of California, Berkeley.

Jacobson, Steven A. 1984. Yup'ik Eskimo Dictionary. Alaska Native Language Center, University of Alaska. 


\section{Plurality of Events in Language and Perception}

Karlsson, Fred. 1999. Finnish: an essential grammar. London, New York: Routledge.

Kimball, Geoffrey D. 1991. Koasati Grammar. Studies in the Anthropology of North American Indians. Lincoln, NE: University of Nebraska Press.

Koffka, Kurt. 1935. Principles of Gestalt Psychology. New York: Harcourt, Brace, and World.

Landman, Fred. 1996. Plurality. In Shalom Lappin, ed., The Handbook of Contemporary Semantic Theory. Oxford: Blackwell.

Landman, Fred. 2000. Events and Plurality. Dordrecht: Kluwer.

Langacker, Ronald W. 1987. Foundations of Cognitive Grammar Vol. 1: Theoretical Prerequisites. Stanford, CA: Stanford University Press.

Michotte, A. E. 1946/1963. The perception of causality. Translated by T. R. Miles and E. Miles. New York: Basic Books.

Nedjalkov, Igor. 1997. Evenki. London, New York:Routledge.

Newtson, Darren. 1973. Attribution and the Unit of Perception of Ongoing Behavior. Journal of Personality and Social Psychology 28(1):28-38

Newtson, Darren, Gretchen Engquist and J. Bois. 1977. The Objective Basis of Behavior Units. Journal of Personality and Social Psychology, 35:847-862.

Wertheimer, Max. 1923. Laws of Organization in Perceptual Forms. First published as Untersuchungen zur Lehre von der Gestalt II, in Psycologische Forschung 4:301-350. Translation published in Ellis, W. 1938. A Source Book of Gestalt Psychology pp. 71-88. London: Routledge and Kegan Paul.

Wilder, D. A. 1978a. Effect of Predictability on Units of Perception and Attribution. Personality and Social Psychology Bulletin 4:281-284.

Wilder, D. A. 1978b. Predictability of behaviors, goals, and unit of perception. Personality and Social Psychology Bulletin, 4:604-607.

Xrakovskij, Viktor S. ed. 1997. Typology of iterative constructions. Lincom Studies in Theoretical Linguistics, 4. München: Lincom Europa.

$\mathrm{Yu}$, Alan. 2003. Pluractionality in Chechen. In Proceedings of the $37^{\text {th }}$ annual meeting of the Chicago Linguistic Society.

Zacks, Jeffrey M. 2004. Using Movement and Intentions to Understand Simple Events. Cognitive Science 28:979-1008.

Zacks, Jeffrey M. and Barbara Tversky. 2001. Event structure in perception and conception. Psychological Bulletin 127(1):3-21

University of California, Berkeley

Department of Linguistics

1203 Dwinelle Hall

Berkeley, CA 94720-2650

tess_wood@earthlink.net 